\title{
Excimer laser phototherapeutic keratectomy in conjunction with mitomycin C in corneal macular and granular dystrophies
}

\author{
Ceratectomia fototerapêtica com excimer laser em conjunto com mitomicina $C$ \\ em distrofias granular e macular da córnea
}

Erdem Yuksel $^{1}$, Mehmet Ozgur Cubuk ${ }^{1}$, Hulya Yazicl Eroglu $^{1}$, Kamil Bilgihan ${ }^{1}$

\begin{abstract}
Purpose: To evaluate the visual outcomes, recurrence patterns, safety, and efficacy of excimer laser phototherapeutic keratectomy (PTK) in conjunction with mitomycin C (MMC) for corneal macular and granular diystrophies.

Methods: The patients were divided into two groups. Group 1 included patients with macular corneal dystrophy (MCD) that caused superficial corneal plaque opacities, and Group 2 included patients with granular corneal dystrophy (GCD). Patients in both groups were pre-, peri-, and postoperatively evaluated. The groups were compared in terms of uncorrected visual acuity (VA), best spectacle-corrected $V A$, presence of mild or significant recurrence, and time of recurrence.

Results: Eighteen eyes (nine with MCD and nine with GCD) of 18 patients (10 men and eight women) were included. PTK was performed for each eye that was included in this study. The mean ablation amount was $117.8 \pm 24.4 \mu \mathrm{m}$ and $83.5 \pm$ $45.7 \mu \mathrm{m}$ in MCD and GCD, respectively, $(p=0.18)$. The postoperative improvement of the mean VA was similar between the two groups before recurrences ( $p>0.43)$ and after recurrences $(p>0.71)$. There were no statistically significant differences in the recurrence rate and the recurrence-free period for any recurrence type.

Conclusion: PTK was an effective, safe, and minimally invasive procedure for patients with MCD and GCD. PTK in conjunction with MMC was similarly effective for both groups in terms of recurrence and visual outcomes.
\end{abstract}

Keywords: Photorefractive keratectomy; Corneal dystrophies; Cornea physiopathology; Mitomycin; Visual acuity

\section{RESUMO}

Objetivo: Avaliar os resultados visuais, padrões de recorrência, segurança eeficácia da ceratectomia fototerapêutica (PTK) por excimerlaser em conjunto com mitomicina C (MMC) em distrofias macular e granular da córnea.

Métodos: Os pacientes foram divididos em dois grupos. Grupo 1 incluiu pacientes com distrofia macular de córnea (MCD) que causaram opacidades superficiais corneanas em placa e o grupo 2 incluiu pacientes com distrofia corneana granular (GCD). Todos os pacientes em ambos os grupos foram avaliados no pré, pere pós-operatório. Os grupos foram comparados em termos de acuidade visual (VA) não corrigida, VA melhor corrigida por óculos, presença de recorrência leve ou significativa e o tempo de recorrência. Resultados: Dezoito olhos de 18 pacientes (10 homens e 8 mulheres) foram incluidos no estudo, 9 olhos com MCD e 9 olhos com GCD. Um procedimento de PTK foi realizado em cada olho incluidos neste estudo. A quantidade média de ablação foi 117,8 $\pm 24,4$, $83,5 \pm 45,7 \mu \mathrm{m}$ de MCD e GCD, respectivamente, $(p=0,18)$. A melhorapós-operatória da acuidade visual média foi semelhanteentre os dois grupos antes de as recidivas $(p>0,43)$ e após as recidivas $(p>0,71)$. Não houve diferença estatisticamente significativa na taxa de recorrência ou do perío do livre de recorrência para qualquer tipo de recorrência.

Conclusão: PTK foi um procedimento eficaz, seguro e minimamente invasivo para pacientes MCD e GCD. PTK em conjunto com MMC é igualmente eficaz para ambos os grupos em termos de recorrência e resultados visuais.

Descritores: Ceratectomia fotorrefratica; Distrofias hereditárias da córnea; Córneal fisiopatologia; Mitomicina; Acuidade visual

\section{INTRODUCTION}

Phototherapeutic keratectomy (PTK), approved by the Food and Drug Administration in 1995, is popularly used for treating anterior corneal dystrophies ${ }^{(1)}$. The aim of PTK is to remove opacities affecting visual acuity (VA) and to provide a smooth and stable corneal surface ${ }^{(1)}$. Corneal stromal dystrophies are progressive diseases that appear in adolescence or later ${ }^{(2,3)}$ and usually cause blurry vision and sometimes symptoms of recurrent erosions ${ }^{(2,3)}$. Currently, PTK is the most commonly used to treat stromal dystrophies in the early stages and may be a significant alternative to delay the requirement for penetrating keratoplasty $(\mathrm{PK})^{(4)}$. Macular corneal dystrophy (MCD) is a rare stromal dystrophy that is characterized by superficial gray-white opacities and corneal thinning, which progressively involves the entire stroma from limbus to limbus ${ }^{(3)}$. While MCD is a recessively inherited dystrophy, granular corneal dystrophy (GCD) is a slowly progressive autosomal dominant disorder that is characterized by deposits at different depths in the corneal stroma ${ }^{(5,6)}$. Although the literature has demonstrated that PTK is safe and effective for treating stromal dystrophies, recurrence of the disease and induced refractive error remain the main deficiencies of the procedure ${ }^{(7-9)}$. In addition, mitomycin C (MMC), an alkylating agent, is commonly used in refractive excimer laser surgery to regulate corneal wound healing; it is believed that MMC can prevent or delay recurrence of the disease in corneal dystrophies ${ }^{(9-11)}$.

However, there are still no studies in the literature that evaluated the effect of MMC on PTK in patients with MCD and GCD. Thus, this study aimed to evaluate the visual outcomes, recurrence patterns, safety, and efficacy of excimer laser PTK in conjunction with MMC in corneal macular and granular dystrophies and to compare the results of these two groups.
Funding: No specific financial support was available for this study.

Disclosure of potential conflicts of interest: None of the authors have any potential conflicts of interest to disclose.

Correspondence author: Erdem Yuksel. Gazi University. Faculty of Medicine - Department of Ophthalmology, Ankara - Turkey - E-mail: rdmyksı@yahoo.com 


\section{METHODS}

The study protocol was approved by the Institutional Review Board/ Ethics Board of the Gazi University. We retrospectively reviewed the medical records of all patients with MCD or GCD who underwent PTK at the Refractive Surgery Unit of the ophthalmology department from January 2002 to December 2014. The patients were divided into two groups. Group 1 included patients with MCD that caused superficial corneal plaque opacities, and Group 2 included patients with GCD. The diagnoses of all patients were confirmed by DNA analysis. Patients with significant corneal thinning or edema, previous excimer laser ablation, uveitis, glaucoma, or other significant ocular surface diseases and a follow-up period of less than 6 months previous were excluded.

Patients in both groups were pre-, peri-, and postoperatively examined. The preoperative examination included a complete systemic and ocular history examination and routine ocular examinations such as uncorrected distance VA (UCVA) in logarithm of the minimal angle of resolution (logMAR), best spectacle-corrected distance VA (BSCVA) in logMAR, manifest refraction, slit-lamp biomicroscopy, computerized corneal topography (Sirius 3D Rotating Scheimpflug Camera-Topography System Costruzione Strumenti Oftalmici, Florence, Italy), Goldman applanation tonometry, and indirect ophthalmoscopy. The depth of treatment and total stromal thickness were evaluated using anterior segment optical coherence tomography (Spectralis; Heidelberg Engineering, Heidelberg, Germany) and slit-lamp examination. The depth of ablation was perioperatively noted.

The postoperative evaluation included UCVA, BSCVA, manifest refraction, epithelial closure time, and recurrence of the disease. A loss of one line in BSCVA with deposits noticed during slit-lamp examination was classified as a mild recurrence and recurrent opacities that caused a loss of two or more lines of BSCVA was classified as a significant recurrence.

We compared the two groups in terms of UCVA, BSCVA, presence of mild or significant recurrence, and the time of recurrence. Moreover, we calculated the safety and efficacy indices. The postoperative BSCVA/preoperative BSCVA (logMAR) ratio was defined as the safety index, and the postoperative UCVA/preoperative BSCVA (logMAR) ratio was defined as the efficacy index.

\section{SuRgical teCHNIQUE}

PTK was performed with the SCHWIND ESIRIS excimer laser (SCHWIND eye-tech solutions, Kleinostheim, Germany) under sterile conditions. After administering topical anesthesia (proparacaine 0.5\%; Alcaine ophthalmic solution, Alcon, USA) to the cornea, we placed drapes and a sterile lid speculum. In eyes with a smooth epithelial surface, a transepithelial method was utilized; however, in eyes with an irregular epithelial surface, the epithelium was mechanically removed with a spatula followed by excimer laser ablation. An ablation zone of $6.5 \mathrm{~mm}$ with no transition zone was used for all eyes with a pulse rate of $200 \mathrm{~Hz}$. After approximately three-quarters of the expected ablation had been applied, the surgeon assessed the density and depth of the remaining diffuse stromal haze using the slit-lamp biomicroscopy. When necessary, an additional PTK was performed, and the total amount of ablation was recorded at the end of the procedure. Balanced salt solution was applied during the ablation to smooth the process. A $2.0 \times 4.0-\mathrm{mm}$ cellulose sponge pledget that was soaked with $0.02 \%(0.2 \mathrm{mg} / \mathrm{mL}) \mathrm{MMC}$ was placed on every eye for $30 \mathrm{~s}$. A 3-diopter anti-hyperopia treatment was applied after 100 microns of stromal ablation according to the manufacturer of the excimer laser.

After the procedure, a lotrafilcon A bandage contact lens (AIR-OPTIX Night \& Day, Alcon, USA) was placed on the eye; patients were treated with moxifloxacin eye drops (Vigamox ophthalmic solution, Alcon, USA) five times a day, preservative-free artificial tears five times a day, and $0.01 \%$ fluorometholone (FML; Allergan, USA) eye drops four times a day. The contact lens was removed after the epithelial defect healed. All patients were examined every 2 weeks for 1 month, every 4 weeks for 3 months, and then every 3 months.

SPSS software version 20.0 for Windows was used for statistical analysis. Snellen VA was converted to logMAR units for statistical analyses. Comparisons between groups or variables were calculated with nonparametric tests; the Mann-Whitney U test was used for unpaired samples, and the Wilcoxon test was used for paired samples. A p value of $<0.05$ was considered statistically significant.

\section{RESULTS}

\section{Preoperative data}

This study analyzed 18 eyes, including nine with MCD and nine with GCD, of 18 patients (10 men and 8 women). All patients underwent PTK for the removal of diffuse stromal haze without any complications; these procedures were performed in all eyes (100\%) that were included in this study. The demographic and preoperative data are shown in table 1.

\section{Perioperative data}

The mean ablation amount was $117.8 \pm 24.4 \mu \mathrm{m}$ in MCD and $83.5 \pm 45.7, \mu \mathrm{m}$ in GCD ( $p=0.18)$. An anti-hyperopia treatment was performed in two eyes in Group 1 and two eyes in Group 2 ( $p=0.63$ ).

\section{Postoperative data \\ Visual acuity}

BCVA significantly improved after PTK in both groups before mild recurrences ( $p=0.02$ for $M C D ; p=0.03$ for $G C D$ ); however, there was no statistical difference in BCVA at the end of the follow-up period $(p=0.11$ and $p=0.39$, respectively), as shown in table 3 and figures 1 and 2. The postoperative BCVA data are defined in table 3 and graph 1. The postoperative improvement in mean VA was similar between the two groups both before recurrences ( $p>0.43$ ) and after recurrences $(p>0.71)$.

Table 1. Demographic and preoperative data of patients with MGD and GCD

\begin{tabular}{lccc}
\hline & MCD & GCD & P* \\
\hline Sex (M/F) & $5 / 4$ & $5 / 4$ & 0.56 \\
Age & $40.8 \pm 17.70$ & $24.00 \pm 4.30$ & 0.08 \\
UCVA & $0.7 \pm 0.30$ & $0.40 \pm 0.29$ & 0.04 \\
BSCVA & $0.7 \pm 0.34$ & $0.33 \pm 0.31$ & 0.05 \\
SE (D) & $-5.9 \pm 7.20$ & $-1.80 \pm 2.40$ & 0.16 \\
Keratometry (D) & $45.3 \pm 1.80$ & $44.50 \pm 1.10$ & 0.44 \\
Pachymetry (mm) & $456.0 \pm 79.00$ & $509.00 \pm 46.40$ & 0.16 \\
Follow-up & $22.0 \pm 36.90$ & $20.00 \pm 14.10$ & 0.54 \\
\hline
\end{tabular}

$\mathrm{MCD}=$ macular corneal dystrophy; $\mathrm{GCD}=$ granular corneal dystrophies; UCVA= uncorrected distance visual acuity; $\mathrm{BSCVA}=$ best spectacle-corrected distance visual acuity; $M=$ men; $F=$ female.

${ }^{*}=$ the comparison of preoperative data of MGD and GCD, Mann-Whitney U test, $(p>0.05)$.

Table 2. Peroperative ablation amounts

\begin{tabular}{lccc}
\hline & MCD & CGD & P* \\
\hline Ablation amount & $117.8 \pm 24.4$ & $83.5 \pm 45.7$ & 0.18 \\
Hymetropic ablation & 2 eyes & 2 eyes & 0.51
\end{tabular}

$\mathrm{MCD}=$ macular corneal dystrophy; GCD= granular corneal dystrophies.

* = the comparison of perioperative data MGD and GCD; Mann-Whitney $U$ and Chi-square test, $p>0.05$. 


\section{Mild and significant recurrences}

The postoperative recurrence rates are shown in table 4 . Mild recurrences occurred after $5.6 \pm 1.4$ months in MCD (five patients) and $6.6 \pm 1.5$ months in GCD (three patients); a significant recurrence was observed in one patient in Group 1 after 22 months and in one patient in group 2 after 20 months. Two eyes with significant recurrences demonstrated no improvement in VA after a repeat PTK.

\section{Table 3. Preoperative and postoperative BCVA values of the two} groups

\begin{tabular}{|c|c|c|c|}
\hline & $\begin{array}{c}\text { Preoperative } \\
\text { BSCVA }\end{array}$ & $\begin{array}{l}\text { Postoperative } \\
\text { BSCVA (BR) }\end{array}$ & $\begin{array}{c}\text { Postoperative } \\
\text { BSCVA (AR) }\end{array}$ \\
\hline \multirow[t]{2}{*}{ MCD } & $0.70 \pm 0.34$ & $0.45 \pm 0.3$ & $0.45 \pm 0.25$ \\
\hline & & $\mathrm{p}: 0.02$ & $\mathrm{p}: 0.1$ \\
\hline \multirow[t]{2}{*}{ GCD } & $0.33 \pm 0.30$ & $10.13 \pm 0.27$ & $0.25 \pm 0.32$ \\
\hline & & p:0.03 & $\mathrm{p}: 0.4$ \\
\hline$p$ & 0.06 & 0.02 & 0.08 \\
\hline
\end{tabular}

MCD = macular corneal dystrophy; GCD = granular corneal dystrophies; BSCVA= best spectacle corrected distance visual acuity in logMAR; $B R=$ before the recurrences; $A R=$ after recurrences Wilcoxon signed ranks test $(p<0.05)$ Mann-Whitney $U$ test $(p>0.05)$.
Although an earlier and higher rate of mild recurrence was observed in $M C D$, there was no statistically significant difference in the recurrence rate and recurrence-free period for any recurrence type $(p=0.6)$.

\section{Safety and efficacy index}

There was no statistical difference between the two groups in terms of efficacy and safety indices. The calculated efficacy index was $0.94 \pm 0.42$ in MCD and $1.2 \pm 1.9$ in GCD, and the safety index was $0.74 \pm$ 0.35 in MCD and $0.92 \pm 1.5$ in GCD ( $p>0.5$ and $p>0.63$, respectively).

\section{Hypermetropic recurrence}

The mean hyperopic shift was statistically higher in MCD $(2.8 \pm 3$ diopters (D)) than in GCD $(0.7 \pm 1.3)(p=0.03)$, as shown in table 4. In addition, there was no correlation between the mean ablation amount and mean hyperopic shift.

\section{DISCUSSION}

MMC is an alkylating agent that regulates corneal wound healing and is commonly used in refractive excimer laser surgery to reduce corneal haze. Furthermore, MMC is used to prevent or delay corneal deposits in corneal dystrophies ${ }^{(9-11)}$. However, there is limited knowledge regarding the recurrence of corneal deposits associated with MCD
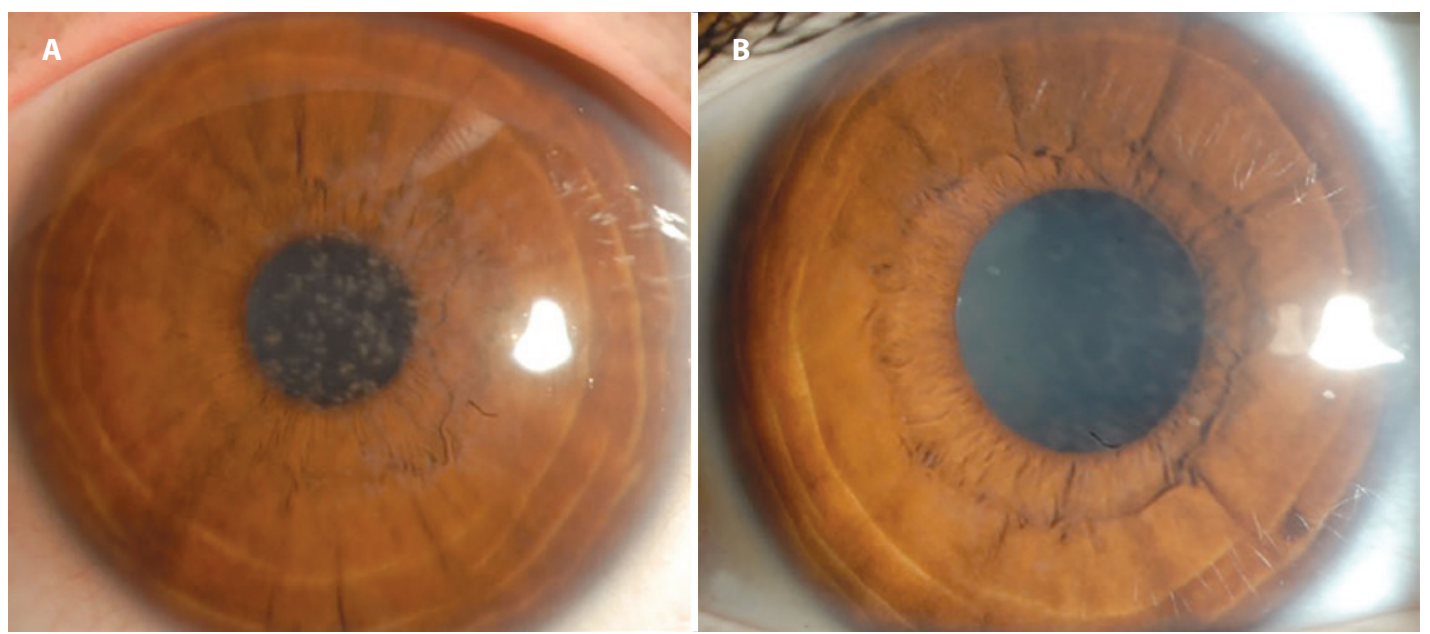

Figure 1. A) Preoperative clinical photograph showing the right eye of a patient with granular dystrophy. BSCVA (best spectacle-corrected visual acuity) was 7/10. B) Six months after PTK, a clinical photograph showing the right eye of the same patient with granular dystrophy. BSCVA was 10/10.
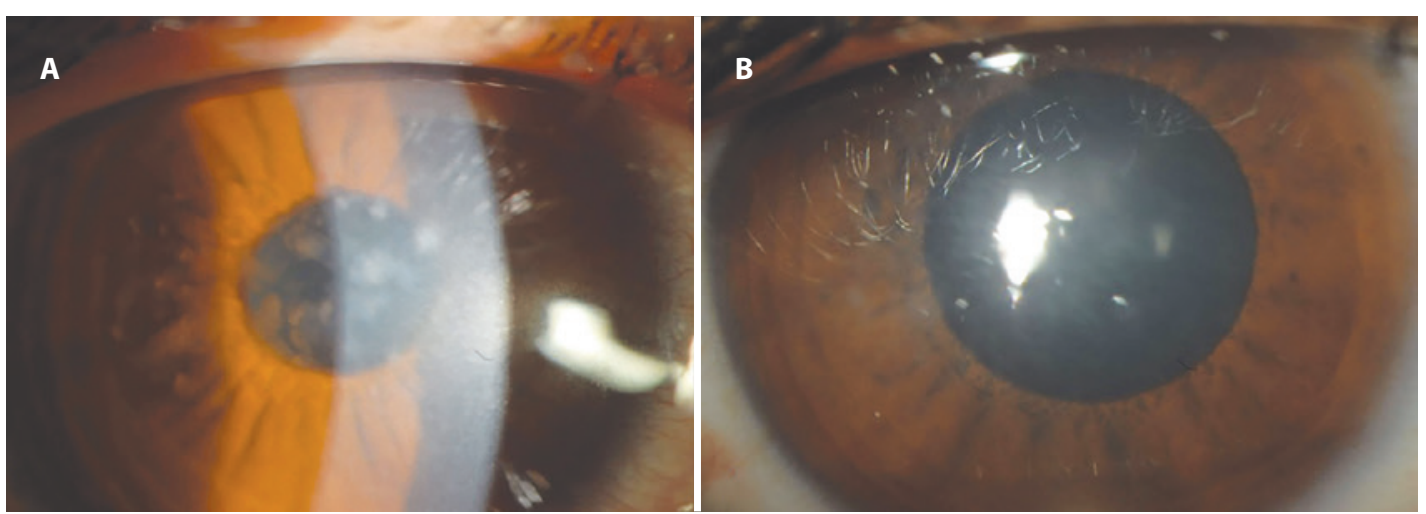

Figure 2. A) Preoperative clinical photograph showing the right eye of a patient with macular dystrophy. BSCVA was 6/10. B) Six months after PTK, a clinical photograph showing the right eye of the same patient with macular dystrophy. BSCVA was 10/10. 


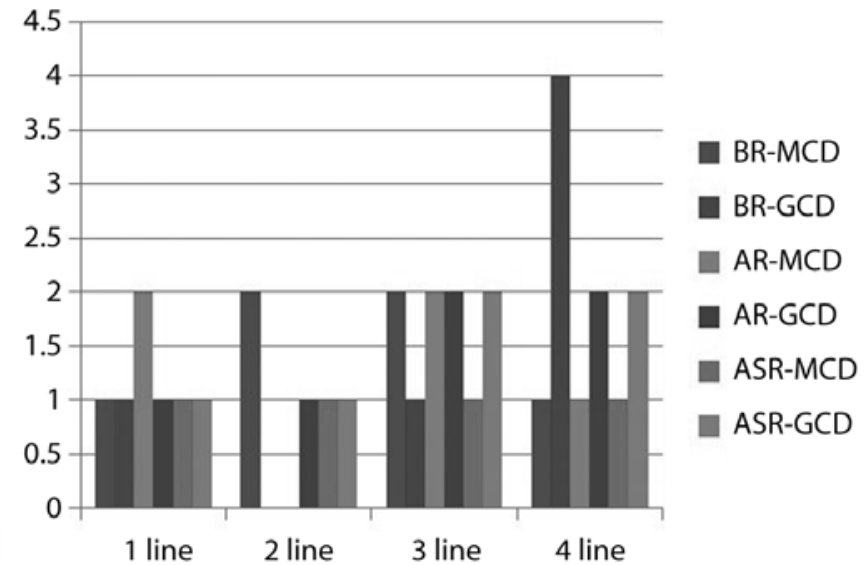

$\mathrm{BR}-\mathrm{MCD}=$ Before recurrences macular corneal dystrophy; $\mathrm{BR}-\mathrm{GCD}=$ before recurrences granular corneal dystrophy; $A R-M C D=$ after recurrences macular corneal dystrophy; $A R-G C D=$ after recurrences granular corneal dystrophy; $\mathrm{ASR}-\mathrm{MCD}=$ after significant recurrences macular corneal dystrophy; ASR-GCD = after significant recurrences granular corneal dystrophy.

Graph 1. Postoperative BCVA improvement.

Table 4. Postoperative recurrence rates

\begin{tabular}{lccc}
\hline & MCD & CGD & P \\
\hline Mild recurrence & 5 eyes of 9 (55.5\%) & 3 eyes of 9 (33.4\%) & 0.60 \\
Time to recurrence (mild) & $5.6 \pm 1.4$ months & $6.6 \pm 1.5$ months & 0.60 \\
Significant recurrence & 1 eye of 9 (11.1\%) & 1 eye of 9 (11.1\%) & 0.60 \\
Time to recurrence (mild) & 22 months & 20 months & \\
Hymetropic shift & $2.8 \pm 3$ D & $0.7 \pm 1.3$ & 0.03 \\
\hline
\end{tabular}

$\mathrm{MCD}=$ macular corneal dystrophy; GCD= granular corneal dystrophies; Mann-Whitney U test; Chi-square test ( $p>0.05)$.

and GCD after PTK in conjunction with $0.02 \%$ MMC. In MCD, intracytoplasmic accumulations of glycosaminoglycans occur within the keratocytes; in GCD, eosinophilic depositions of mutant transforming growth factor beta-induced protein (TGFBIp) extracellularly accumulate. It is well documented that the recurrence rate of MCD is much higher and occurs earlier than in GCD after PTK treatment ${ }^{(12-14)}$. Chen and $\mathrm{Xie}^{(12)}$ observed that the time for development of a significant recurrence was 12.4 and 19.7 months after PTK in MCD and GCD, respectively. Redd et al. ${ }^{(14)}$ reported a higher, milder, and more significant recurrence rate in MCD than in GCD. However, MMC was not used after PTK in these studies. MMC induces keratocyte apoptosis and might decrease or delay the accumulation of glycosamnoglycans within he keratocytes, thereby consequently decreasing the MGD recurrence rate and extending the recurrence time. We observed that the recurrence rate and time in our study were different than those in other studies. While the mild recurrence rate was $55.5 \%$ in MGD, the recurrence rate was $33.4 \%$ in GCD, which was not statistically significant. Moreover, a significant recurrence occurred in one patient in each group (11.1\%). The mean development time of mild recurrence was $5.6 \pm 1.4$ months in MCD and $6.6 \pm 1.5$ months in GCD. A significant recurrence was observed in one patient with MCD after 22 months and in one patient with GCD after 20 months.

Another important concern in corneal dystrophies is VA. Both MGD and GCD can cause blurry vision and glare. PTK can be safely and less aggressively used to improve vision and reduce glare in corneal stromal dystrophies; furthermore, it provides faster visual improvement ${ }^{(4)}$. This study demonstrated comparable visual outcomes after PTK in patients with MGD and GCD. Although the preoperative BCVA was statistically higher in GCD, statistically significant visual improvement was achieved before recurrences occurred in both groups and was not statistically different between both groups. However, there was no statistical difference between the preoperative and postoperative BCVA over a mean follow-up of $22 \pm 36.9$ months for MGD and 20 \pm 14.1 months for GCD. The most likely cause of was the occurrence of recurrences. This outcome was comparable with a study by Hafner et al., (15) which achieved a BCVA increment from $0.3 \pm 0.2$ to $0.6 \pm 0.1$ in MGD. Wagoner and Badr ${ }^{(16)}$ also reported that BCVA increased from 20/80 to 20/30 in MCD. As in these studies, Redd et al. ${ }^{(14)}$ revealed an increase in BCVA from $0.46 \pm 0.25$ to $0.51 \pm 0.27$ in MCD and GCD with PTK, although this was not statistically different.

A hyperopic shift is a well-described side effect of PTK for corneal dystrophies. In this study, the mean hyperopic shift was statistically higher in MCD ( $2.8 \pm 3 \mathrm{D})$ than in GCD $(0.7 \pm 1.3)$ ( $p=0.03)$. An anti-hyperopia treatment was performed in two eyes in each group.

In this study, the depth of PTK was set according to the slit-lamp findings during the treatment. If the remaining diffuse stromal haze was dense, PTK was continued until most of the opacity was cleared. As expected, the mean ablation was larger in MGD $(117.8 \pm 24.4 \mu)$ than in GCD $(83.5 \pm 45.7 \mu)$ because MCD involves the deeper layers of the cornea; however, there was no correlation between the mean ablation size and mean hyperopic shift.

PTK is an effective, safe, and minimally invasive procedure for patients with MCD and GCD. PTK in conjunction with MMC was similarly effective in both groups in terms of recurrence and visual outcomes. The application of MMC after PTK can delay the recurrence time in MCD and avoid the requirement for keratoplasty.

\section{REFERENCES}

1. Rapuano CJ. Excimer laser phototherapeutic keratectomy. Int Ophthalmol Clin. 1996; 36(4):127-36.

2. Nassaralla BA, Garbus J, McDonnell PJ. Phototherapeutic keratectomy for granular and lattice corneal dystrophies at 1,5 to 4 years. J Refract Surg. 1996;12(7):795-800.

3. Droutsas DD, Tsioulias GE, Kotsiras JE, Koufala CJ, Lambropoulos JE. Phototherapeutic keratectomy in macular corneal dystrophy with recurrent erosions. J Refract Surg. 1996;12(2):293-4.

4. Kim EK. PTK in corneal dystrophy. Cornea. 2004;23(4):323-4.

5. Hong JP, Kim TI, Chung JL, Huang D, Cho HS, Kim EK. Analysis of deposit depth and morphology in granular corneal dystrophy type 2 using fourier domain optical coherence tomography. Cornea. 2011;30(7):729-38.

6. Seitz B, Behrens A, Fischer M, Langenbucher A, Naumann GO. Morphometric analysis of deposits in granular and lattice corneal dystrophy: histopathologic implications for phototherapeutic keratectomy. Cornea. 2004;23(4):380-5.

7. Dinh R, Rapuano CJ, Cohen EJ, Laibson PR. Recurrence of corneal dystrophy after excimer laser phototherapeutic keratectomy. Ophthalmology. 1999;106(8):1490-7.

8. Dogru M, Katakami C, Yamanaka A. Refractive changes after excimer laser phototherapeutic keratectomy. J Cataract Refract Surg. 2001;27(5):686-92. Comment in: J Cataract Refract Surg. 2002;28(2):207-8. J Cataract Refract Surg. 2002;28(5):732.

9. Ayres BD, Hammersmith KM, Laibson PR, Rapuano CJ. Phototherapeutic keratectomy with intraoperative mitomycin $\mathrm{C}$ to prevent recurrent anterior corneal pathology. Am J Ophthalmol. 2006;142(3):490-2.

10. Kim Tl, Pak JH, Chae JB, Kim EK, Tchah H.Mitomycin C inhibits recurrent Avellino dystrophy after phototherapeutic keratectomy. Cornea. 2006;25(2):220-3.

11. Ha BJ, Kim TI, Choi SI, Stulting RD, Lee DH, Cho HS, et al. Mitomycin C does not inhibit exacerbation of granular corneal dystrophy type $\|$ induced by refractive surface ablation. Cornea. 2010;29(5):490-6.

12. Chen $M$, Xie L. Features of recurrence after excimer laser phototherapeutic keratectomy for anterior corneal pathologies in North China. Ophthalmology. 2013;120(6): 1179-85.

13. Fagerholm P. Phototherapeutic keratectomy: 12 years of experience. Acta Ophthalmol Scand. 2003;81(1):19-32

14. Reddy JC, Rapuano CJ, Nagra PK, Hammersmith KM. Excimer laser phototherapeutic keratectomy in eyes With corneal stromal dystrophies with and without A corneal graft. Am J Ophthalmol. 2013;155(6):1111-8.

15. Hafner A, Langenbucher A, Seitz B. Long term results of phototherapeutic keratectomy with 193-nm excimer laser for macular corneal dystrophy. Am J Ophthalmol. 2005; 140(3):392-6.

16. Wagoner MD, Badr IA. Phototherapeutic keratectomy for macular corneal dystrophy J Refract Surg. 1999;15(4):481-4 